\title{
Long COVID-19 Syndrome Precaution and Management
}

\section{Abdelfattah HM*}

Al Abbassia psychiatric Hospital, Egypt

*Corresponding author: Hesham Maged abdelfatah, Neuropsychiatry Doctor, the Egyptian Ministry of Health, Al Abbassia psychiatric Hospital, Cairo, Egypt, Email: hesham.maged2011@ yahoo.com

\section{Research Article}

Volume 5 Issue 2

Received Date: May 24, 2021

Published Date: July 02, 2021

DOI: $10.23880 / \mathrm{mhrij}-16000146$

\section{Abstract}

COVID-19 virus defined as illness caused by a novel coronavirus which first discovered in Wuhan City, China. And On January 30, 2020, the WHO awarded the global health emergency. This is a review of COVID-19's highly affects on almost all the organs and how we precaution and management as the COVID-19 causes many systemic abnormalities like inflammation, endotheliitis, vasoconstriction, hypercoagulability, edema and Lymphocytopenia, with elevated D-dimer, and disseminated intravascular coagulation. Deep vein thrombosis and venous, thrombosis with pulmonary embolization, systemic and pulmonary arterial thrombosis, embolism are reported, ischemic stroke changes, and myocardial infarction are reported also. it can lead to acute coronary syndrome, with heart failure and myocarditis, arrhythmias. Kidney affection was usually secondary to systemic allover disturbances. Stroke may occurred. Delirium and seizures symptoms are common. Impaired the tastes are reported with Psychological disturbances are commonly, Lactate dehydrogenase may be elevated. Many skin manifestations including patchy erythematous rash are noticeable, One of the biggest barriers standing in the way of ending the pandemic the misinformation about the COVID-19 vaccines. At this critical time the Demand for vaccines very effective as it rigorously tested and found to be safe, also Vaccines have no effect on recipients' genetic material and not effect on fertilization also Antibodies from are estimated to last two to four months, so those who have had a previous infection still get this vaccinated.

Keywords: Long Covid-19; Cytokine Storm; Acute Kidney Injury; Acute Respiratory Distress Syndrome; Myocarditis; Encephalitis; Psychosis; Dementia; Vaccination

Abbreviation: AKI: Acute Kidney Injury; PTSD: PostTraumatic Stress Disorder.

\section{Introduction}

The COVID-19 It has rapidly spread all around the continents courses, many affected people and many death. On May 11, 2021, 11:52 GMT The total COVID-19 cases was about 160 million people and number of deaths was about 3million and half people and the number of recovery was about 137 million and half with active case in this time was about 19 million cases divided between $99.4 \%$ mild cases and $0.6 \%$ critical cases, sources: Worldometer most system becoming affects is the respiratory system, However, In critically patients, multiple systems are affected. The COVID-19 binds angiotensin converting enzyme 2 receptors that's receptors found in the vascular endothelial cells, of the body organs, [1]. Disturbances of coagulation process and vascular endothelium are contributed to the injury of multiple organs. Cardiac and renal is commonly affected among the patients who die. Injury and damage to the organs may long lasting after the acute infection has 
disappeared. Different organs may be affected at different times. Long Coved is defined by The National Institute for Health and Care Excellence, as the presence of symptoms that develop during or following an infection with COVID-19 which continue for about 12-weeks or more and are not explained by an alternative diagnosis. This includes both ongoing symptomatic COVID-19 (from 4 to 12 weeks) and "Post-COVID Syndrome" (12-weeks or more) [2]. There are two stages known as Long COVID: Ongoing symptomatic COVID-19, that's symptoms last 4-12 weeks. Post COVID-19 syndrome, symptoms that last for more than 3 months and can't be explained by another diagnosis (Figures $1 \& 2$ ).

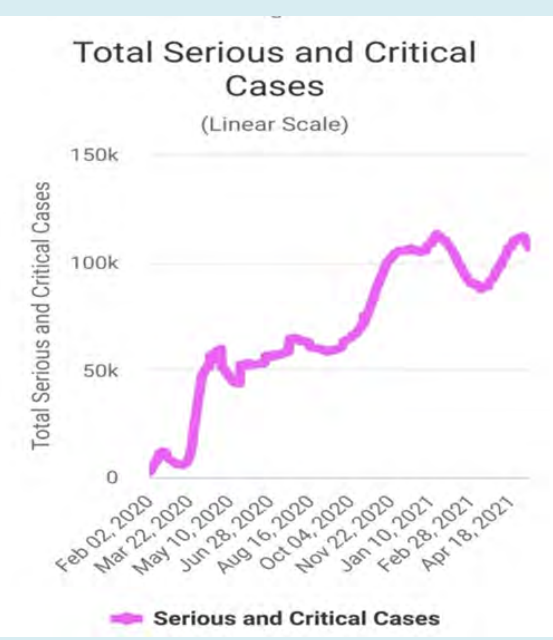

Figure 1: Total serous and critical COVID-19 patients.

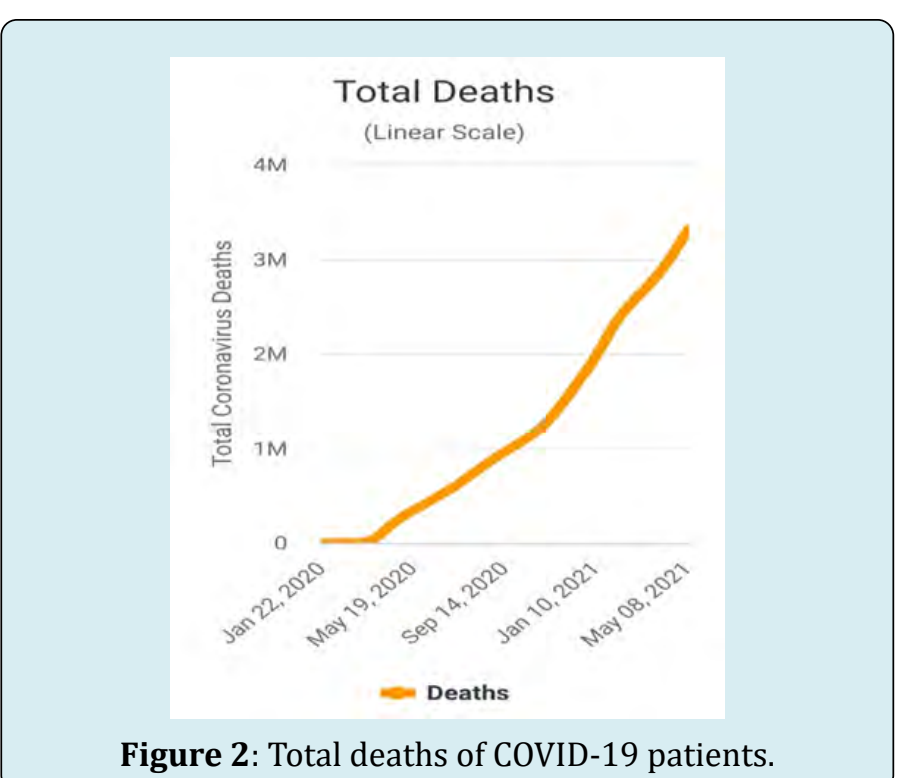

\section{Discussion}

COVID-19 lead to production of cytokines by the white blood cells. This abnormal response lead to systemic inflammatory processes and acute respiratory, with multiorgan damages, shock, and finally death. Inflammatory process may increase even when the viral load of infection is decreased.COVID-19 infects origin endothelial cells and leading to diffuse and massive lymphocytic endotheliitis, which cause vasoconstriction [3].

\section{Effect on the Liver and GIT}

The liver increases secretion of procoagulant substances. C-reactive protein was elevated. Cytokine storm and massive systemic inflammation are associate with lymphocytopenia that a cause elevates in the D-dimer, which was a prognostic. G.I.T effects: symptoms likely loss of appetite, nausea, vomiting, diarrhea, and abdominal pain (Figure 3).

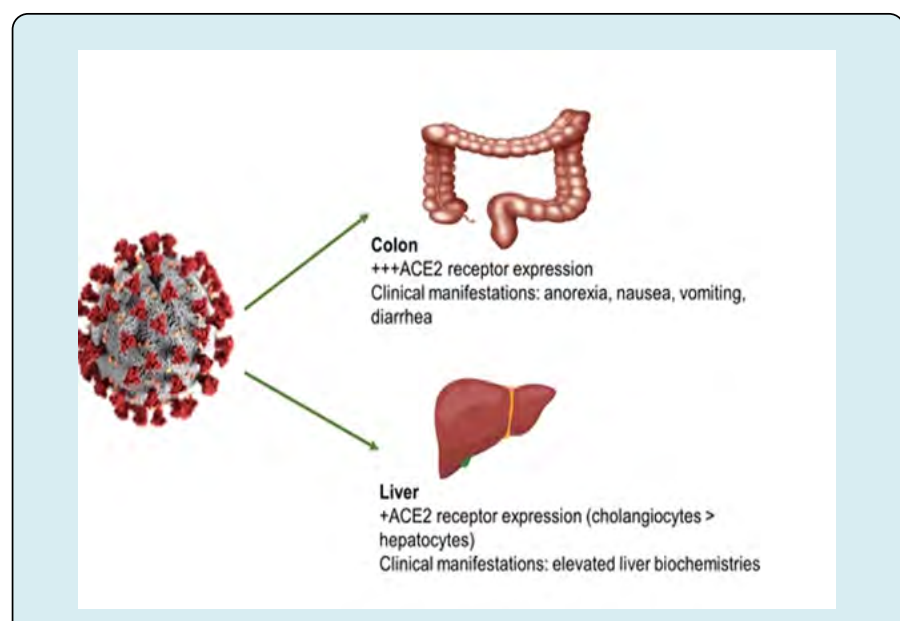

Figure 3: Liver injury in the setting of COVID19-related illness.

\section{Precaution and Management}

We recommend thromboprophylaxis [4,5] or anticoagulants oral form, as the Heparins bind tightly to the spike COVID-19 proteins stopping the entry of the virus into cells and also acted as down regulate the immune activation also GIT symptomatic treatments.

\section{Effect on Chest}

In the acute stage the patients have classic diffuse alveolar damage without organization and fibrosis [6,7]. It is caused by disruption of endothelial, alveolar cells. This leads to fluid and cellular exudation, Acute fibrinous and pneumonia are also observed [8]. On chest CT, findings of subpleural and peripheral areas of ground-glass opacity (G.G.O) and consolidation are present in patients with COVID-19 [9,10] (Figure 4). 


\section{Mental Health \& Human Resilience International Journal}

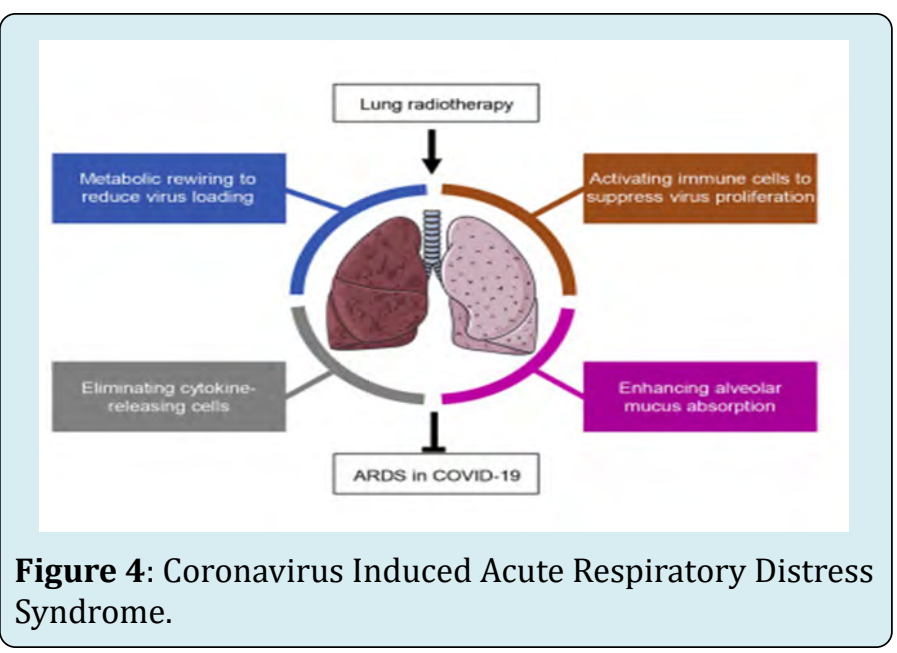

\section{Precaution and Management}

Several ways are available for managing respiratory insufficiency. As Oxygen via high-flow nasal cannula and noninvasive ventilators. British Thoracic Society guidelines define the target range for oxygen saturation as $94-98 \%$ and a level of $92 \%$ or below as requiring supplementary oxygen (unless the patient is in chronic respiratory failure [11].

\section{Effect on heart}

Can occur in the absence of pulmonary and other complications $[12,13]$. Ischemic injury can occur in patients with coronary artery disease, the primary cause of the former two is plaque rupture and thrombosis (Figure 5).

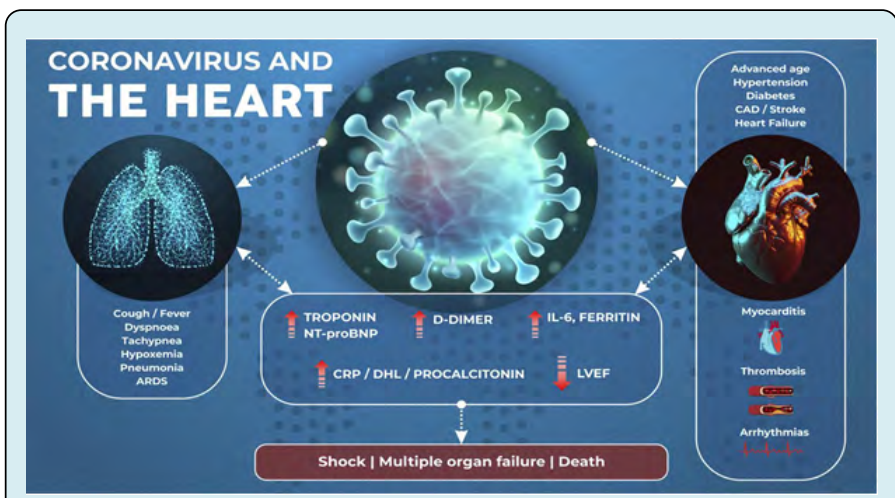

Figure 5: Coronavirus and the Heart.

\section{Precaution and Management}

Emergency clinicians should be aware of those cardiovascular complications when evaluating and treatment the patients COVID-19 and may admit to ICU unit and may usage the mechanical circulatory system in cardiogenic or mixed shock.

\section{Effect on Kidney}

COVID-19 complicates the treatment of patients on dialysis [14]. The virus is found in glomerular cells, tubular epithelium, and acute kidney injury (AKI) is commonly secondary to systemic disturbances including diabetes, hypertension, and coagulopathy. Cytokine storms can cause drastic hypoperfusion. Acute kidney injury is also caused due to hyperventilation or medications including antivirals (Figure 6).

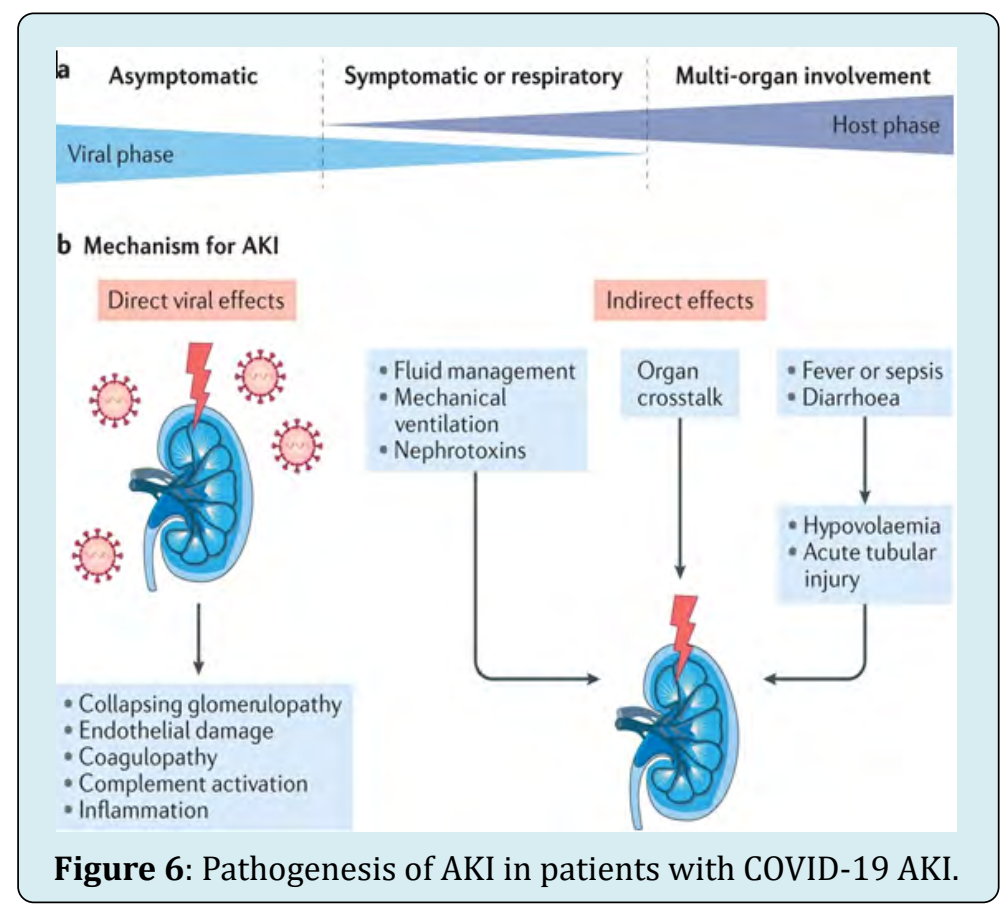




\section{Mental Health \& Human Resilience International Journal}

\section{Precaution and Management}

Individualized fluid and haemodynamic management based on dynamic assessment of cardiovascular status for critically ill patients with COVID-19 and balanced crystalloids as initial management for the expansion of intravascular volume in patients at risk of AKI or with AKI unless a specific indication exists for the use of other fluids, and limiting nephrotoxic drug exposure where possible and with careful monitoring when nephrotoxins are required.

\section{Effect on Brain}

Meningitis, encephalitis indicating viral invasion of the CNS. Neurological manifestation can occur with respiratory or other symptoms impairment [15-17]. Symptoms like dizziness, headache, impaired consciousness, contusion status, delirium, and cognitive impairment. Also the Cytokine storm can cause brain inflammation with edema causing seizure-like. Brain Stroke may found due to thrombus in the cerebral artery [18]. Cerebral hemorrhage, Ataxia and seizure also may found. Cranial nerves impairment may also found. Anosmia and dysgeusia are reported [19]. Neuritis and muscle weakness, fatigue, pain, tingling and numbness are observed in many patients (Figure 7).

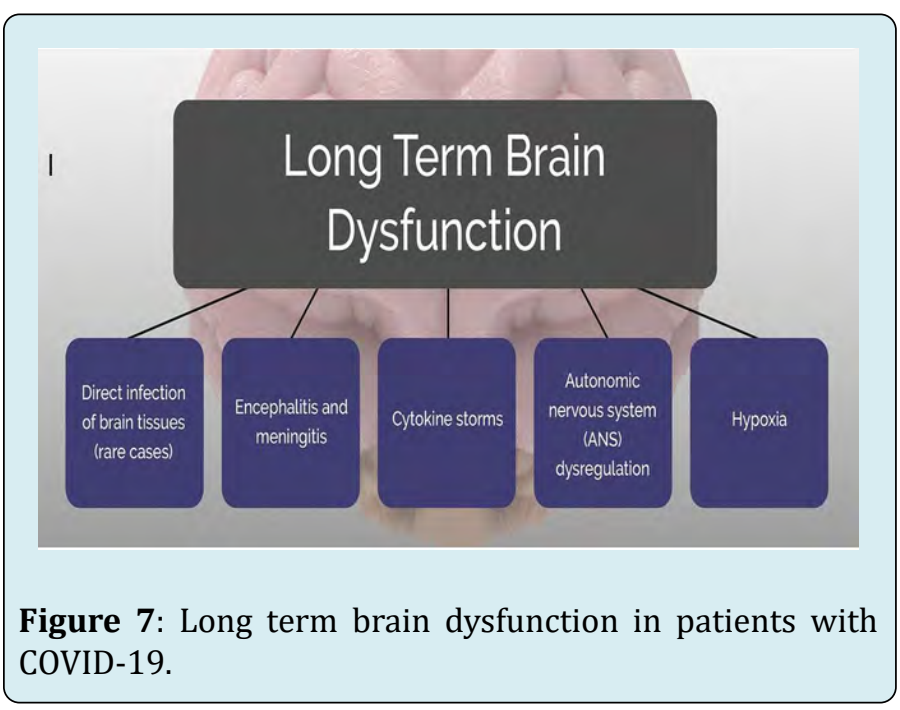

\section{Precaution and Management}

Proper investment and careful monitoring of CNS symptoms with Perform aerobic exercise to improve brain health and healthy diet including olive oil, fruits and vegetables, nuts and beans, and whole grains has been proven to improve thinking, memory. and brain health with Avoiding alcohol and drugs also Sleep well so the brain and body can clear out toxins and work toward healing, Participate in social activities, benefit our moods, and helping our thinking and memory as well, engaging in novel, cognitively stimulating activities; listening to music; practicing mindfulness; and keeping a positive mental attitude.

\section{Effect on the Eyes}

About $30 \%$ of hospitalized patients develop ocular abnormalities like conjunctivitis [20].

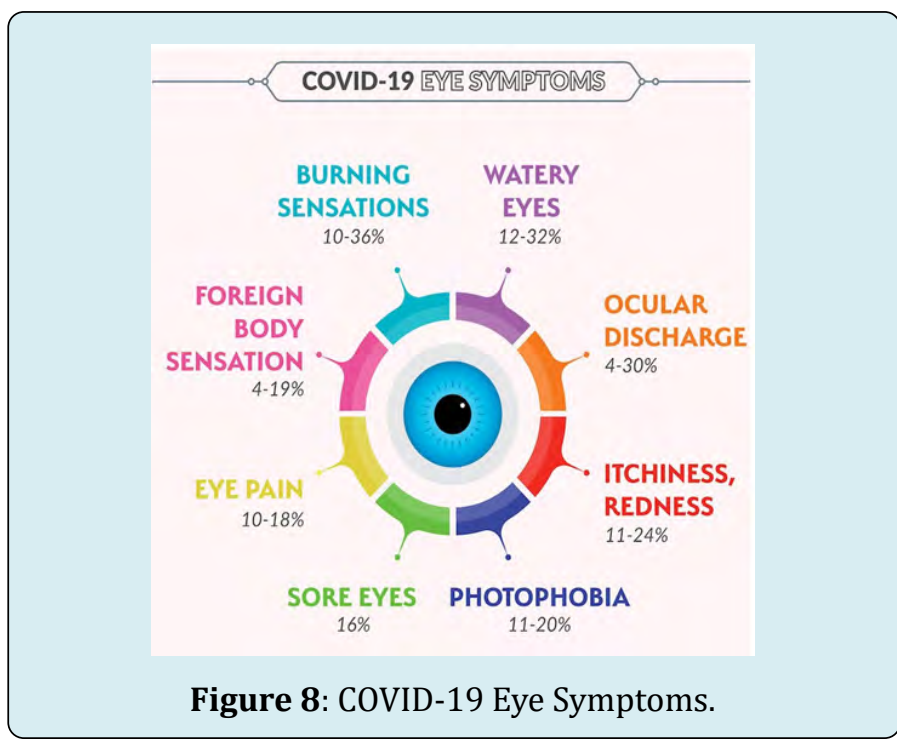

\section{Precaution and Management}

As of March 18, 2020, the American Academy of Ophthalmology has urged all ophthalmologists to produce only urgent or emergent care to scale back the danger of SARS-CoV-2 transmission and to conserve disposable medical supplies. Within the absence of great eye pain, decreased vision, or light sensitivity, many patients will be managed remotely with a shot of frequent preservative-free artificial tears, cold compresses, and lubricating ophthalmic ointment. a brief course of topical antibiotics are often added to forestall or treat bacterial super infection supported the patient's symptoms and risk factors.

\section{Effect on Skin}

Skin disorders are likely to other viruses and chronic inflammations like acne or eczema or psoriasis. the majority have patchy erythematous rash [21]. Some have widespread urticaria or few also have chickenpox-like fluid-filled vesicles or blisters. They can have measles-like rashes (Figure 9). 


\section{Mental Health \& Human Resilience International Journal}

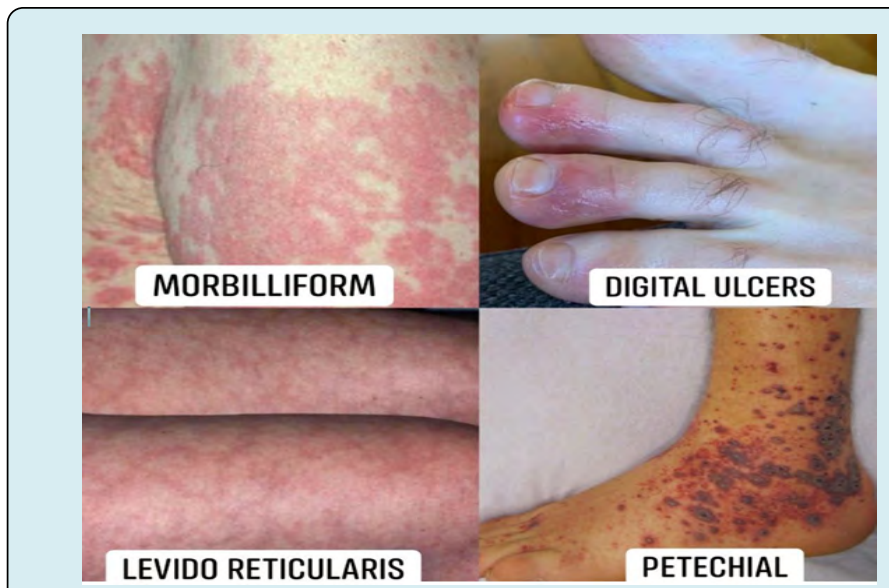

Figure 9: Commonest Skin Rashes to Look for with COVID-1.

\section{Precaution and Management}

Low-dose systemic corticosteroids as a therapeutic option for COVID-19-associated urticarial rash. Indeed, lowdose systemic corticosteroids, combined with nonsedating antihistamines, can help in managing the hyperactivity of the system in COVID-19, not only to regulate urticaria, but also to boost possibly the survival rate in COVID-19.

\section{Psychological Effects}

Because of financial pressure and social isolation many psychological problems can arise. They can be delayed by months. There is an increase in "deaths of despair" from substance misuse or suicide. The risk is greater among persons with dementia. After discharge from ICU, a $30 \%$ of the patients inattention, disorientation problems, or poorly movements in response to questions [22]. Some patients who recover suffering from mental health problems. Like anxiety, major depression episodes, post-traumatic stress disorder (PTSD). Long effects can include development of Alzheimer's or Parkinson's disease (Figure 10).

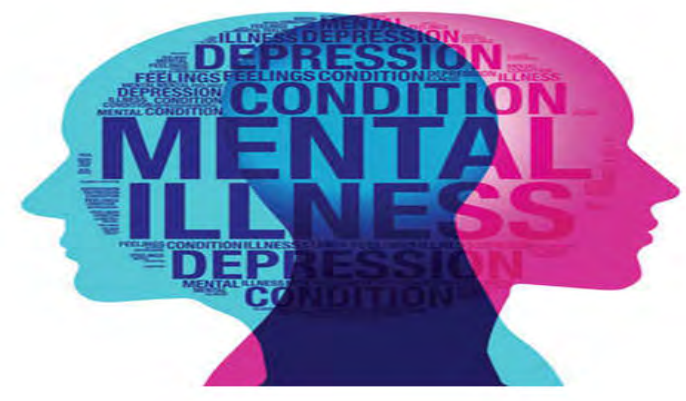

Figure 10: COVID-19 exacerbated Depression, OCD, anxiety, Suicidality.

\section{Precaution and Management}

Healthy Ways to address Stress: Take breaks from watching, reading, or taking note of news stories, including those on social media. It's good to learn, but hearing about the pandemic constantly is upsetting. Consider limiting news to simply a pair times each day and disconnecting from phone, TV, and computer screens for ages. Try to eat healthy, well-balanced meals. Exercise regularly. Get lots of sleep. Avoid excessive alcohol, tobacco, and substance use. Make time to unwind. Attempt to do another activity you enjoy. Connect with others. Talk with people you trust about your concerns and the way you're feeling. Connect along with your community- or faith-based organizations. While social distancing measures are in situ, try connecting online, through social media, or by phone or mail. Helping others cope. Finely, COVID-19 vaccination is now offering a way to transition out of this phase of the pandemic. COVID-19 vaccination keep you from getting infected by COVID-19 also keep you from getting seriously ill even if you got COVID-19. Getting vaccinated yourself also protect people around you, Once you are fully vaccinated, you can start doing more you should keep using all the tools available to protect yourself and others until you are fully vaccinated. Also it's an easy and safe way protection and the risk of severe illness or death from COVID-19 far outweighs any benefits of natural immunity. The vaccinations will protect you by creating an antibody response without having to experience sickness. And will be an important tool to stopping the pandemic as none of the COVID-19 vaccines can make you infected with COVID-19.

\section{Conclusion}

Long COVID-19 is a serious problem as the virus binds to ACE2 receptors present all over the body and can affect virtually every system of the body. It can cause cytokine 


\section{Mental Health \& Human Resilience International Journal}

storm which can lead to deaths. Different organs may be affected. Viral load and Inflammation, platelet activation, hypercoagulability, endothelial dysfunction constriction of blood vessels, stasis, hypoxia, and muscle immobilization contribute to the complications. The respiratory system is commonly affected. Coronary syndrome and congestive heart failure, myocarditis may be present. Patients who are on angiotensin converting enzyme inhibitors and angiotensin II receptor blockers should continue. AKI is usually secondary to systemic disturbances. Meningitis, encephalitis, encephalopathy, stroke, and delirium are also observed. Impaired sense of smell and taste are observed. Eyes can also be sources of viral infection. Mentally problems are common among patients as well as providers. GI symptoms are observed. Patchy skin erythematous rash is commonest skin manifestation. Thus, COVID-19 can affect virtually any organ in the body, so vaccinations are the smart way to control our lives and ending this disaster (Figure 11).

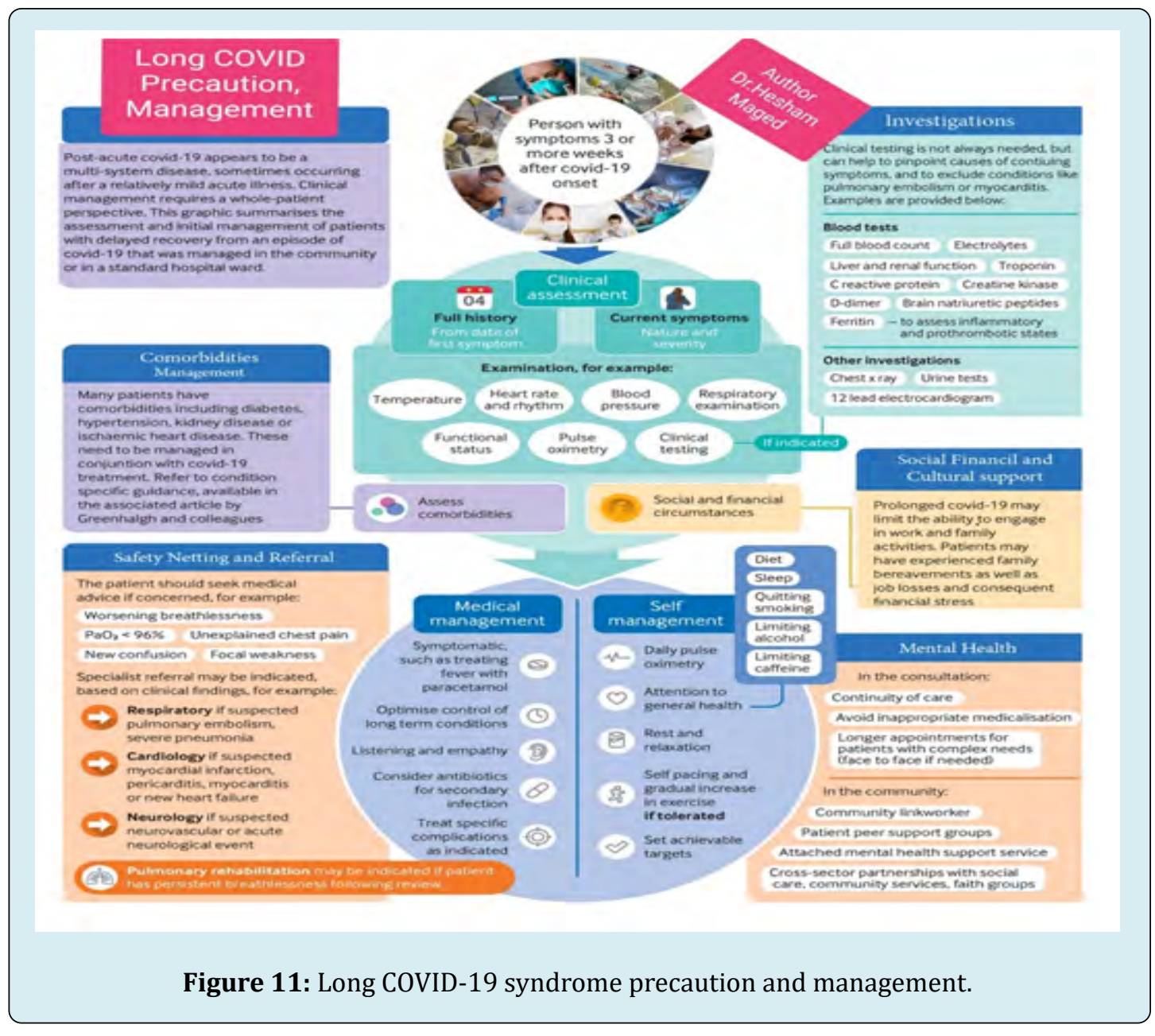

\section{Data Availability Statement}

The original contributions generated for the study are included within the article/supplementary materials, further inquiries are often directed to the corresponding authors.

\section{Conflict of Interest}

The authors declare that the research was conducted within the absence of any commercial or financial relationships that might be construed as a possible conflict of interest.

Author Contributions: All authors approved the ultimate manuscript.

\section{Acknowledgments}

We wish to present my special due to Liver Institute in Menoufia, and Abbassia asylum, and to the Azhar University EGYPT, with a virtual platform of young researchers for their support during the preparation of the paper. 


\section{Mental Health \& Human Resilience International Journal}

\section{References}

1. Wadman M, Frankel JC, Kaiser J, Matacic C (2020) How does coronavirus kill? Clinicians trace a ferocious rampage through the body, from brain to toes. World Health Oraganization.

2. (2020) COVID-19 Rapid Guideline: Managing The Longterm Effects of COVID-19. National Institute for Health and Care Excellence.

3. Varga Z, Flammer A, Steiger P, Haberecker M, Andermatt R, et al. (2020) Endothelial cell infection and endotheliitis in COVID-19. Lancet 395(10234): 1417-1418.

4. (2020) Coronavirus disease 2019 (COVID-19) treatment guidelines.

5. Alhazzani W, Moller M, Arabi Y, Loeb M, Gonget MN, et al. (2020) Surviving sepsis campaign: guidelines on the management of critically ill adults with coronavirus disease 2019 (COVID-19) Intensive Care Med 46(5): 854-887.

6. Barton L, Duval E, Stroberg E, Ghosh S, Mukhopadhyay S (2020) COVID-19 autopsies, Oklahoma, USA. Am J Clin Pathol 153(6): 725-733.

7. Xu Z, Shi L, Wang Y, Zhang J, Huang L, et al. (2020) Pathological findings of COVID-19 associated with acute respiratory distress syndrome. Lancet 8(4): 420-422.

8. Copin M, Parmentier E, Duburcq T, Poissy J, Mathieu D (2020) Time to consider histologic pattern of lung injury to treat critically ill patients with COVID-19 infection. Intensive Care Med 46(6): 1124-1126.

9. Marini J, Gattinoni L (2020) Management of COVID-19 respiratory distress. JAMA 323(22): 2329-2330.

10. Ferreyro B, Angriman F, Munshi L, Sorbo LD, Ferguson ND, et al. (2020) Association of noninvasive oxygenation strategies with all-cause mortality in adults with acute hypoxemic respiratory failure. A systematic review and meta-analysis. JAMA 324(1): 57-67.

11. Madjid M, Naeini PS, Solomon S, Vardeny O (2020)
Potential effects of coronaviruses on the cardiovascular system: a review. JAMA Cardiol 5(7): 831-840.

12. Akhmerov A, Marban E (2020) COVID-19 and the heart. Circ Res 126(10): 1443-1455.

13. Alberici F, Delbarba E, Manenti C, Econimo L, Valerio F, et al. (2020) Management of patients on dialysis and with kidney transplantation during the SARS-CoV-2 (COVID-19) pandemic in Brescia, Italy. Kidney Int Rep 5(5): 580-585.

14. Helms J, Kremer S, Merdji H, Clere Jehl R, Schenck M, et al. (2020) Neurologic features in severe SARS-CoV-2 infection. N Engl J Med 382(23): 2268-2270.

15. Lahiri D, Ardila A (2020) COVID-19 pandemic: a neurological perspective. Cureus 12(4): 7889.

16. Mao L, Jin H, Wang M, Hu Y, Chen S, etal (2020) Neurologic manifestations of hospitalized patients with coronavirus disease 2019 in Wuhan, China. JAMA Neurol 77(6): 1-9.

17. Oxley T, Mocco J, Majidi S, Kellner CP, Shoirah H, et al. (2020) Large-vessel stroke as a presenting feature of Covid-19 in the young. N Engl J Med 382(20): 60.

18. Spinato G, Fabbris C, Polesel J, Cazzador D, Borsetto D, et al. (2020) Alterations in smell or taste in mildly symptomatic outpatients with SARS-CoV-2 infection. JAMA 323(20): 2089-2090.

19. Wu P, Duan F, Luo C, Liu Q, Xingguang Qu, et al. (2020) Characteristics of ocular findings of patients with coronavirus disease 2019 (COVID-19) in Hubei province, China. JAMA Ophthalmol 138(5): 575-578.

20. Recalcati S (2020) Cutaneous manifestations in COVID-19: a first perspective. J Eur Acad Dermatol 34(5): 212-213.

21. Darlenski R, Tsankov N (2020) Covid-19 pandemic and the skin - what should dermatologists know?. Clin Dermatol 38(6): 785-787.

22. Pfefferbaum B, North C (2020) Mental health and the Covid-19 pandemic. N Engl J Med 83(6): 510-512. 